\title{
The Establishment of Blouse'S Parameter Constraint Database Based on Pattern Automatic Generation
}

\author{
Lina Cui \\ Quanzhou normal university, Quanzhou, China
}

\begin{abstract}
Keywords: pattern, automatic generation, blouse, parameterization, database
Abstract. This study takes fast pattern generating as the goal and takes blouse pattern as the research ob-ject, then raises up the parametric design method based on numerical geometric constraint, and take constraint solving for each part of the blouse pattern, furthermore, this paper uses numerical method of geometry con-straint to complete the process of parametric design for clothing patterns, then blouse pattern's complete pa-rametric constraint database and rule base is established, and more important, the study establish data foun-dation for apparel pattern automatic generation system and interactive modification.
\end{abstract}

\section{Instructions}

The clothing industry is a labor-intensive industry. The technical personnel who engage in the clothing structure are clear that, most of the work in the fashion design process is repetitive work. In order to reduce the repeated work of operators as well as improve the production efficiency, researchers put forward the automatic generation of intelligent pattern design ideas, and further introduce the expert system for apparel industry. For example, through the CAD expert system interface, we input a desired style, body size, type size, various parts of the relation data, the expert system will automatically draw the qualified pattern that we need in the computer thus, this will greatly reduces the design difficulty, speeds up the pattern structure design speed, improves the efficiency and ensures the accuracy of the design. Intelligent pattern automatic generation is the development trend of the clothing CAD system.[1][2]

We know that although the garment pattern design is usually the plane structure design, it is still closely associated with the overall effect of clothing, so clothing pattern design process can replaced by a variety of different parameters or parameters relationship. So in order to realize the automatic generation of the garment pattern, the most important problem we have to solve is the parameterization of pattern structure lines.[3][4]

\section{The Determination of Pattern Parametric Design Method}

\subsection{The concept of parametric design}

Parametric design is to use a set of parameters to define the size of geometry graph and restrain the size relationship; the modification of the design results is driven by parameters. And parametric design for clothing pattern is to use a set of structure size sequence obtained by the pattern parameter constraint; there is certain corresponding relationship between parameters and pattern control sizes. When parameters are given different values, we can drive the original pattern into a new pattern. The parametric design is direct application of the technology that computer aided design of artificial intelligence technology. Through this technology, the shape size and positioning size of the designing shape is defined by variable symbols, rather than a set of constant data. Controlled by the shape's size, only through modify the shape's parameters data; we can make the body shape change without having to change the shape itself.

\subsection{The determination of the pattern parametric design method}

In recent years, there have been made many research results in the field of parameters design, and there is more and more parametric design methods. The methods that more commonly used are: modeling method based on the relationship, modeling method based on feature entity, intelligent method based on geometric reasoning and numerical method based on the geometric constraints. 
The numerical method based on geometric constraints is the method that according to the given constraints, firstly represents the relationship of a numerical model with a set of equations, then takes mathematical solutions of equations and obtains the model corresponding to the coordinate value, finally determines the parametric geometric details of the products. And garment pattern designs also rely mainly on mathematical formulas that corresponding to the computation, and finally generate the irregular geometric figures. Therefore, the numerical method for geometric constraint parametric design is the most feasible method.

\section{Determination of the Blouse Pattern}

Blouse is women's most basic styles, which can very simple but elegant, fashion and changeable. Through blouse pattern's making, we can have a basic understanding of women's pattern design process. This study selected the most common style blouse as the research object and its characteristics is slim in the waist, two waist darts on front and back of blouse, big lapel. Style and structure is shown below, the specifications for the blouse is 160/84A.

Table 1. Drawing standard for women's blouse(unit: $\mathrm{cm}$ )

\begin{tabular}{ccccccc}
\hline parts & size & Long & $\begin{array}{c}\text { chest } \\
\text { circumference }\end{array}$ & $\begin{array}{c}\text { shoulder } \\
\text { breadth }\end{array}$ & $\begin{array}{l}\text { back } \\
\text { length }\end{array}$ & $\begin{array}{c}\text { neck } \\
\text { circumference }\end{array}$ \\
\hline standard & $160 / 84 \mathrm{~A}$ & 65 & 94 & 39 & 38 & 38 \\
\hline
\end{tabular}
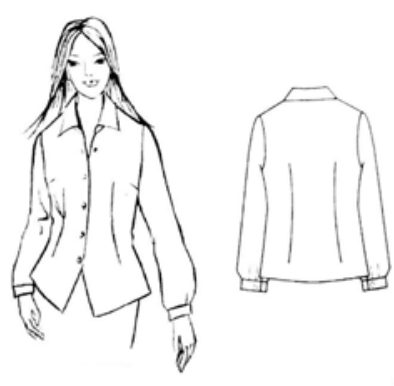

Figure1. Blouse style

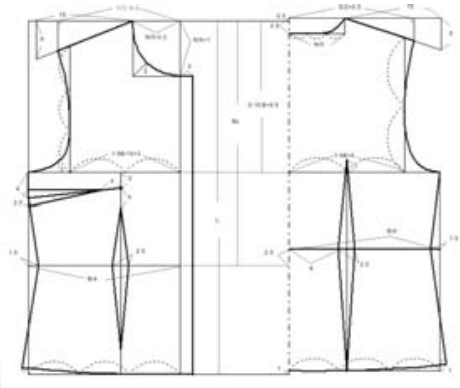

Figure 2. Blouse’s pattern

\section{The Establishment of Blouse Pattern Parameter Constraint Database}

\subsection{The establishment of the parameters}

This study takes basic blouse's pattern parameters as the example, for other female shirts and other styles of dress; the operation process can refer to the following steps.

Table2 blouse pattern parameter table(unit: $\mathrm{cm}$ )

\begin{tabular}{cccc}
\hline Order number & parameter name & parameter type & data \\
\hline 1 & size & specification parameter & $160 / 84 \mathrm{~A}$ \\
2 & Long(L) & specification parameter & 55 \\
3 & chest circumference(B) & specification parameter & 94 \\
4 & shoulder breadth(S) & specification parameter & 39 \\
5 & neck circumference(N) & specification parameter & 38 \\
6 & back length(BL) & technical parameter & 38 \\
7 & front dart & modeling parameter & 2.5 \\
8 & back dart & modeling parameter & 2.5 \\
10 & neck width & modeling parameter & 6.5 \\
11 & sleeve height & Complex parameter & 23.6 \\
\hline
\end{tabular}




\begin{tabular}{cclc}
\hline 12 & back width & Complex parameter & 18 \\
13 & back arc length of neck & geometric parameter & 9.65 \\
14 & front arc length of neck & geometric parameter & 12.74 \\
15 & front sleeve cage arc & geometric parameter & 22.95 \\
16 & back sleeve cage arc & geometric parameter & 23.49 \\
\hline
\end{tabular}

\subsection{The establishment of blouse pattern parameter constraint database}

According to the data relation and the database requirement, the constraint coordinates of each structure point are given according to the data relation and the database.
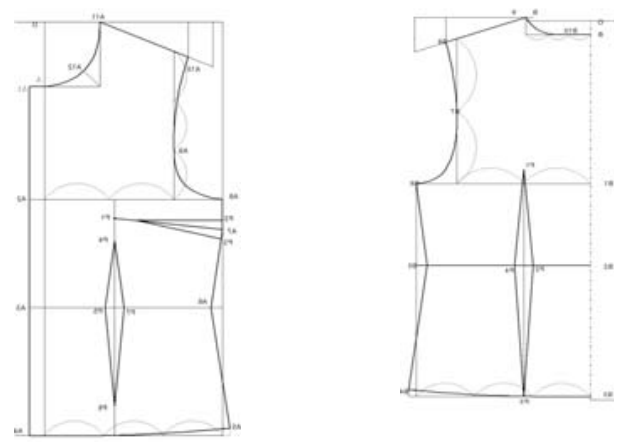

Figure. 3 The coordinates code of each constraint point on the front and back

Table 3. Each structure point 's parametric constraint database of front blouse pattern (unit: $\mathrm{cm}$ )

\begin{tabular}{|c|c|c|c|c|c|c|c|}
\hline $\begin{array}{l}\text { Point } \\
\text { code }\end{array}$ & $\begin{array}{l}\text { Series } \\
\text { number }\end{array}$ & Coordinate(X) & Coordinate(Y) & $\begin{array}{l}\text { Last } \\
\text { point }\end{array}$ & $\begin{array}{l}\text { Next } \\
\text { point }\end{array}$ & $\begin{array}{c}\text { Next } \\
\text { two point }\end{array}$ & law \\
\hline $\mathrm{O}$ & $\mathrm{O}$ & 0 & 0 & & $\mathrm{~A}$ & A1 & 0 \\
\hline A & 1 & 2 & $\mathrm{~N} / 5+1$ & $\mathrm{O}$ & A1 & $\mathrm{A} 2$ & 0,1 \\
\hline A1 & 2 & 2 & $\mathrm{~N} / 5+1$ & A & A2 & A3 & 1,1 \\
\hline A2 & 3 & 2 & $0.15 B+9.5$ & A1 & A3 & A4 & 1,1 \\
\hline A3 & 4 & 2 & BL & A2 & A4 & A5 & 1,1 \\
\hline A4 & 5 & 2 & $\mathrm{~L}$ & A3 & A5 & A6 & 1,2 \\
\hline A5 & 6 & $-(\mathrm{B} / 4+1)$ & L-1 & A4 & A6 & A7 & 2,1 \\
\hline A6 & 7 & $-(\mathrm{B} / 4-1.5)$ & $\mathrm{BL}$ & A5 & A7 & A8 & 1,1 \\
\hline A7 & 8 & $-B / 4$ & $0.15 B+9.5+4$ & A6 & A8 & A9 & 1,1 \\
\hline A8 & 9 & $-\mathrm{B} / 4$ & $0.15 B+9.5$ & A7 & A9 & A10 & 1,2 \\
\hline A9 & 10 & $-(0.15 B+3)$ & $\begin{array}{l}0.15 B+9.5- \\
(S / 2-N / 5-0.2) \tan 22^{\circ}\end{array}$ & A8 & A10 & A11 & 2,2 \\
\hline A10 & 11 & $-(\mathrm{S} / 2-0.5)$ & $(\mathrm{S} / 2-\mathrm{N} / 5-0.2) \tan 22^{\circ}$ & A9 & A11 & A12 & 2,1 \\
\hline A11 & 12 & $-(\mathrm{N} / 5-0.3)$ & 0 & A10 & A12 & A & 1,2 \\
\hline A12 & 13 & $-\left(\mathrm{N} / 5-0.3-3 \sin 45^{\circ}\right)$ & $\mathrm{N} / 5+1-3 \sin 45^{\circ}$ & A11 & A & & 2,2 \\
\hline $\mathrm{P} 1$ & 14 & {$\left[\begin{array}{l}- \\
{[(0.15 B+3) / 2+0.7]}\end{array}\right.$} & $0.15 B+9.5+3$ & A7 & $\mathrm{P} 2$ & P3 & 1,1 \\
\hline $\mathrm{P} 2$ & 15 & $-B / 4$ & $0.15 B+9.5+2.75$ & $\mathrm{P} 1$ & $\mathrm{P} 2$ & $\mathrm{P} 1$ & 1,1 \\
\hline P3 & 16 & $-B / 4$ & $0.15 B+9.5+5.5$ & $\mathrm{P} 2$ & $\mathrm{P} 1$ & & 1,1 \\
\hline
\end{tabular}




\begin{tabular}{|c|c|c|c|c|c|c|c|}
\hline P4 & 17 & {$[(0.15 B+3) / 2+0.7]$} & $0.15 B+9.5+7$ & $\mathrm{P} 1$ & P5 & P6 & 1,1 \\
\hline P5 & 18 & $\begin{array}{l}{[(0.15 \mathrm{~B}+3) / 2+0.7-} \\
1.25]\end{array}$ & BL & $\mathrm{P} 4$ & P6 & P7 & 1,1 \\
\hline P6 & 19 & {$\left[\begin{array}{c}- \\
{[(0.15 B+3) / 2+0.7]}\end{array}\right.$} & SL-5 & P5 & P7 & $\mathrm{P} 4$ & 1,1 \\
\hline P7 & 20 & $\begin{array}{l}\text { [(0.15B+3)/2+0.7+1.2 } \\
\text { 5] }\end{array}$ & BL & P6 & P4 & & 1,1 \\
\hline & able 4. & Each structure point 's par & netric constraint datab & of back b & Ise patter & unit: cm) & \\
\hline $\begin{array}{l}\text { Point } \\
\text { code }\end{array}$ & $\begin{array}{l}\text { Series } \\
\text { number }\end{array}$ & Coordinate $(\mathrm{X})$ & Coordinate $(\mathrm{Y})$ & $\begin{array}{l}\text { Last } \\
\text { piont }\end{array}$ & $\begin{array}{l}\text { Next } \\
\text { point }\end{array}$ & $\begin{array}{l}\text { Next } \\
\text { two } \\
\text { point } \\
\end{array}$ & law \\
\hline $\mathrm{O}$ & 0 & 0 & 0 & & A & A1 & 0 \\
\hline B & 1 & 0 & 2 & $\mathrm{O}$ & A1 & A2 & 0,1 \\
\hline B1 & 2 & 0 & $0.15 B+9.5$ & A & A2 & A3 & 1,1 \\
\hline B2 & 3 & 0 & BL-2.5 & A1 & A3 & A4 & 1,1 \\
\hline B3 & 4 & 0 & SL-1 & A2 & A4 & A5 & 1,2 \\
\hline B4 & 5 & $\mathrm{~B} / 4+1$ & SL-2 & A3 & A5 & A6 & 2,1 \\
\hline B5 & 6 & B/4_1.5 & BL-2.5 & A4 & A6 & A7 & 1,1 \\
\hline B6 & 7 & $\mathrm{~B} / 4$ & $0.15 B+9.5$ & A5 & A7 & A8 & 1,2 \\
\hline B7 & 8 & $0.15+4$ & $\begin{array}{l}0.15 \mathrm{~B}+9.5-(\mathrm{S} / 2- \\
\mathrm{N} / 5) \tan 18^{\circ}\end{array}$ & A6 & A8 & A9 & 2,2 \\
\hline B8 & 9 & $\mathrm{~S} / 2$ & $(\mathrm{~S} / 2-\mathrm{N} / 5) \tan 18^{\circ}$ & A7 & A9 & A10 & 2,1 \\
\hline B9 & 10 & $\mathrm{~N} / 5$ & -0.5 & A8 & A10 & A & 1,2 \\
\hline B10 & 11 & $\mathrm{~N} / 15$ & 2 & A9 & A & & 2,2 \\
\hline $\mathrm{P} 1$ & 12 & $(0.15 B+4) / 2$ & $0.15 B+9.5-2$ & & $\mathrm{P} 2$ & P3 & 1,1 \\
\hline $\mathrm{P} 2$ & 13 & $(0.15 B+4) / 2-1.25$ & BL-2.5 & $\mathrm{P} 1$ & P3 & $\mathrm{P} 4$ & 1,1 \\
\hline P3 & 14 & $(0.15 B+4) / 2$ & BL-1 & $\mathrm{P} 2$ & P4 & $\mathrm{P} 1$ & 1,1 \\
\hline $\mathrm{P} 4$ & 15 & $(0.15 B+4) / 2+1.25$ & BL-2.5 & P3 & $\mathrm{P} 1$ & & 1,1 \\
\hline
\end{tabular}

Note: the points which are on the contour line marked with A(front) and B (back), other modeling point marked with $\mathrm{P}$, the connection method between one point and the last and next point respectively denote by data $0,1,2$,they respectively denote point, line and curve.

\section{Conclusion}

Today, a major development trend for clothing pattern design is intelligence, and parameterization is one of the core modules for realizing the automation of clothing pattern design. This study takes blouse pattern as the research object, use numerical method of geometry constraint to complete the process of parametric design for clothing patterns, then this paper establishes the complete parametric constraint database and rule base of blouse pattern, and establishes the foundation for the blouses pattern automatic generation system and interactive modification .

\section{References}

[1] Wang.Z,Newton.E,R \& Zhang.H.Ease distribution in relation to the X-line style jacket.Part l: Development of a mathematical model.The Textile Institute.2006.(3): 247-256.

[2] Zhang .H\&Zhang.X. Method of automatic generation for tailored clothing pattern, Knitting industry, 2005. 12: 29-31

[3] Wei.G\&Zhang. H.Z.Analysis of the application of parametric design of garment pattern, Tianjin Textile Science \& Technology, 2007, 45(02):34-36

[4] Song.H.H,Research on automatic generation system of men's pattern, Shanghai: Shanghai University of Engineering Science, 2007:35 - 37 